\title{
Priority areas formation of speech competence students of non-philological specialties
}

\author{
Olga Ovsyannikova ${ }^{1}$, Svetlana Bobrova ${ }^{2, *}$, Igor Bocharnikov ${ }^{3}$ \\ ${ }^{1}$ Research center of problems of national security, 15, building 2, Plekhanov street, 119571, Moscow, \\ Russia \\ ${ }^{2}$ Moscow state regional University, 10A, Radio street, 105005, Moscow, Russia \\ ${ }^{3}$ Bauman Moscow state technical University, 5, 2nd Baumanskaya str., 105005, Moscow, Russia
}

\begin{abstract}
The article analyzes the current trends and conditions for the development of students 'speech-thinking abilities and the formation of students' speech competence, and examines modern methods used in the classroom to improve the speech culture of future specialists. The data of the ascertaining experiment showing the level of development of speech competence of students are given. Criteria and factors of speech formation are considered. It is emphasized that the leading principle of educational process management is the formation of motivational factors and reflection of students in terms of the quality of their speech. Promising technologies for the formation of speech competence of specialists are identified. The main direction of development of speech competence of students at the present stage is the formation of speech culture based on linguistic, cultural, situational, professional levels; taking into account the psychological characteristics of specialists, factors of motivation and reflection of students. The leading methods of speech training are teaching methods that correspond to a person-oriented technology, problem tasks (search-game, cognitive-search, role-playing games, discussions), language exercises, emotional-behavioral tasks, and others).
\end{abstract}

\section{Introduction}

Speech competence contributes to the successful activity of a specialist, increasing his activity, solving professional problems, it is one of the main conditions for the formation of a professional's personality. Of course, improving the quality of speech training requires scientifically based content and methodological support. The purpose of this article is to consider promising directions and technologies for the formation of speech competence of students in higher education, methods of speech training and the possibility of their application in the educational process. Identification of promising directions and methods of development and formation of speech competence of future specialists is an actual problem of this research.

E.S. Antonova (2005), E.M. Bastrikova (2005), S.V. Bobrova (2011), M.A. Vasilik (2003) and others addressed the issues of determining the essence of linguistic, linguistic,

\footnotetext{
${ }^{*}$ Corresponding author: bobrova_svetlana@mail.ru
} 
cultural, socio-cultural, and communicative competence.

The works of E.V. Artsishevskaya (2008), N.N. Menkova (2004) and other researchers are devoted to the disclosure of the conceptual characteristics of speech competence. The ideas of O.G. Groholskaya (2001), M.V.Koltunova (2000), S.V. Bobrova (2011), M. A. Mischerina (2011) and others contributed to substantiating the leading role of speech communications in professional competence.

The research of O.A. Anisimova (2010), Yu.V. Vardanyan (1998) and others is devoted to identifying the specifics of communicative competence, structural components, and functions.

Understanding the characteristics of speech competence in the pedagogical aspect was carried out in the comparative analysis of this concept with the culture of speech, linguistic, linguistic, socio-cultural, cultural and communicative competence (T.V. Ivanchikova, 2012).

The source of selection and selection of qualities, knowledge and skills of the content of the criteria of language competence were the works of B.C. Grekhnev (2010), I.A. Zimnaya (2001), V.V. Zankov (1999) and other researchers.

At the same time, the problem of forming the speech competence of future specialists is not fully developed today. Currently, there are only a few scientific studies devoted to the study of certain aspects of this problem (E.V.Buzalskaya (2010), L.V. Merkulova (2006)). These studies are devoted to the development of technologies aimed at developing the speech competence of certain specialists, such as lawyers, economists, and others. The study of this issue was carried out within the framework of the methodology of teaching speech culture in pedagogical and methodological aspects. Foreign specialists paid attention to the issues of speech training of specialists of a certain profile (Beletskaya O. (2016) [1], Lugovskaya E. (2017) [8], Veremeychik (2013) [6]. Systematic studies of the formation of speech competence of future specialists by psychologists and sociologists were not carried out to the full extent. Consequently, the authors have identified a problem field that is located at the intersection of such areas of psychological science as educational psychology and psycholinguistics.

\section{Materials and methods}

The main research methods related to the determination of regularities are theoretical and methodological analysis of the problem, comparative analysis, comparison, mental modeling, empirical research, mathematical methods of data processing that allow to determine stable relationships and relationships, trends of changes, and generalization.

To identify areas of formation and development of speech competence of students, a study of speech activity of specialists was conducted. The methods used in the study evaluated the individual characteristics of students, which were considered in their dynamics and comprehensively in the aspect of their inherent patterns: maturation, development, formation and formation of psychological characteristics. The study, which was conducted at Moscow state regional University, used the method of analyzing the products of students ' activities. The texts that the subjects wrote were analyzed, then the following types of problems that they encountered were highlighted. These difficulties are associated with the formation of spelling, punctuation, grammar, speech skills, as well as analytical skills, which indicators are the structure and generality of the presentation. 


\section{Results}

During the research, the coherence and logic of statements were considered at the speech level. The texts of all students had indicators of connectivity and complexity. Perhaps, on the one hand, this is due to the desire for a broader, holistic presentation of the material, on the other - a reflection of the low level of development of speech activity in modern young people, regardless of the natural predisposition of individuals to abstract logical thinking, characterized by complex mental processing of information. There is a tendency of insufficient attention to the formation of independent analytical thinking skills of students.

Problems associated with the formation of speech competence are caused by many factors: narrow horizons of students, the poverty of their vocabulary, the lack of constant training in writing texts of various types, the utterance of coherent monologues on a particular topic, as well as limited reader interests.

Low performance of the indicator of speech competence of students is manifested in a large number of difficulties (spelling, punctuation, speech) that students experienced. This may be due to the fact that students focus on detailed and in-depth study of new special disciplines and are inattentive to the design of their speech.

The analysis of students 'utterances allowed us to consider both the actual linguistic characteristics of the text at the language, speech and content-semantic levels, and the psychological component of students' speech actions, which includes the operationaldynamic, motivational, cognitive, emotional, regulatory and productive components.

The texts contained a large number of compound, compound sentences, introductory constructions, clarifying, homogeneous sentence members, abbreviations, numerals, proper nouns, and emotionally-colored vocabulary. After working with the texts, the works were analyzed depending on the developed criteria. These studies were entered in tables and subjected to quantitative and qualitative analysis.

In the process of conducting the research, the criterion of structuring the presentation was highlighted. It includes:

1. The presence of introduction, conclusion and main body.

2. the connection Between the parts, the consistency of the presentation.

3. Dividing the text into paragraphs.

4. Completeness of the presentation (availability of all important details).

5. The absence of contradictions between the parts.

The subjects received low scores for this criterion. This indicates a low level of development of analytical and synthetic abilities, which are necessary for specialists in their future activities.

In the course of the study, the criterion of generalization of the presentation was highlighted. It relates to:

1. The ability to convey the content of the text in your own words.

2. The presence of the author's position.

3. The presence of a conclusion that follows from the content of the text.

4. Availability of keywords.

5. The amount of text (within 10 sentences).

As a rule, the students ' speech was characterized by neutrality, generality and abstraction of the lexical units used, low emotionality with the dominance of the means of expressing sthenic emotions, and logical presentation.

The analysis of linguistic characteristics of integral statements of students allows us to consider both the actual linguistic characteristics of the text (at the language, speech and content-semantic levels), and the psychological components of the authors ' speech actions (operational-dynamic, motivational, cognitive, emotional, regulatory and productive). 
Students seriously think and comprehend texts, their statements reflect the depth of understanding $(15 \%)$ of the relevance and complexity of this problem.

At the same time, they, using (though in a small number) emotionally colored lexical units $(8.3 \%)$, more often experience sthenic emotions of uplifting, inspiration, pride, and optimism. In logical, integral texts of students, there is a tendency to display willpower $(13.5 \%)$, plan actions $(17.9 \%)$, and analyze them $(7.6 \%)$ with a small number $(9.1 \%)$ of clarifying and reinforcing expressions.

So, in small-volume, insufficiently complicated, descriptive, logical, holistic, more colored by positive emotions texts of students manifest their volitional efforts, the desire for analysis. Let's consider the average value of the factor of speech competence in students before the introduction of technology for the formation of speech competence (table 1).

Table 1. The average value of the factor of speech competence in students.

\begin{tabular}{|c|c|}
\hline Factors & Average value \\
\hline Spelling skill & 4.1 \\
\hline Punctuation skill & 3.7 \\
\hline Grammatical skill & 4.1 \\
\hline Speech skill & 4.3 \\
\hline Accuracy of the presentation & 4.0 \\
\hline Structure of presentation & 3.1 \\
\hline Generalization of the presentation & 2.9 \\
\hline
\end{tabular}

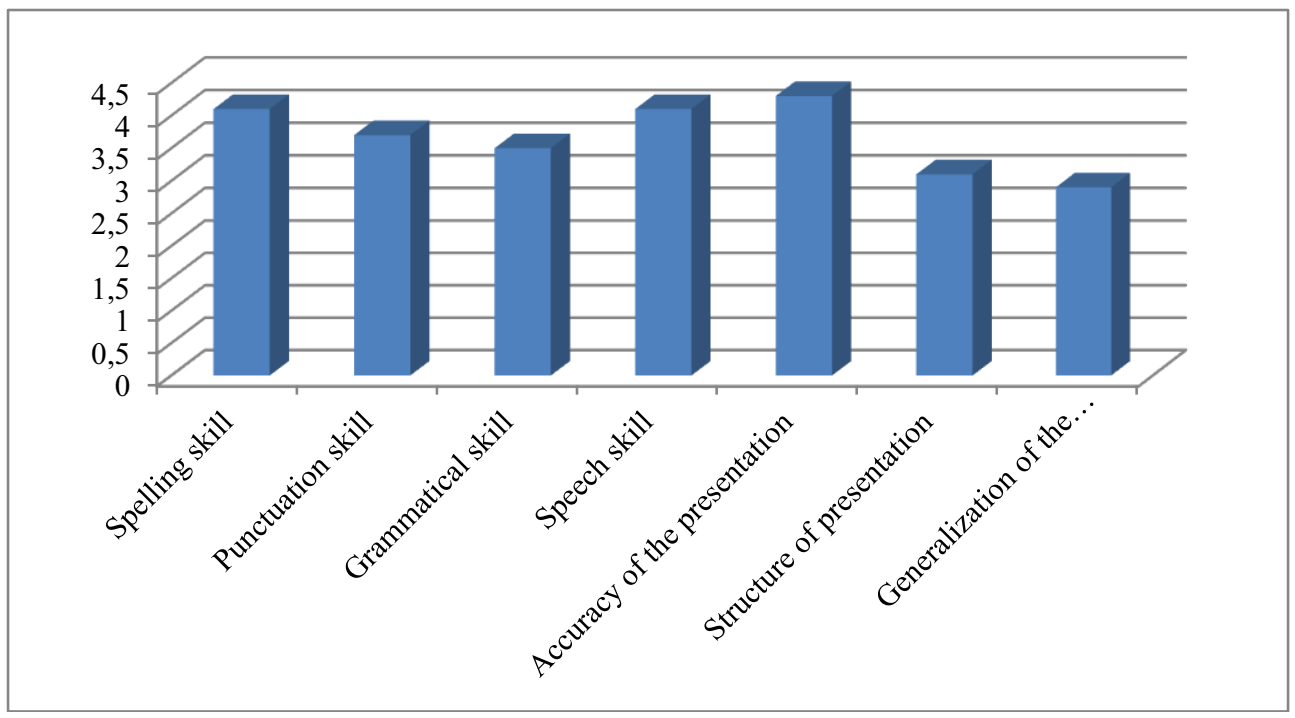

Fig. 1. the Average value of the factor of speech competence in students.

As the results of the study showed, the results of the test subjects were more successful after the use of technology for the formation and development of students ' speech competence. The subjects had fewer difficulties related to the formation of spelling, punctuation, grammar, speech and analytical skills [15], since the classes were designed in such a way as to develop these skills through various exercises and trainings. 
Table 2. The average value of the factor of speech competence in students after the formation experiment.

\begin{tabular}{|c|c|}
\hline Factors & Average value \\
\hline Spelling skill & 4.6 \\
\hline Punctuation skill & 4.3 \\
\hline Grammatical skill & 4.3 \\
\hline Speech skill & 4.7 \\
\hline Accuracy of the presentation & 4.8 \\
\hline Structure of presentation & 4.4 \\
\hline Generalization of the presentation & 3.9 \\
\hline
\end{tabular}

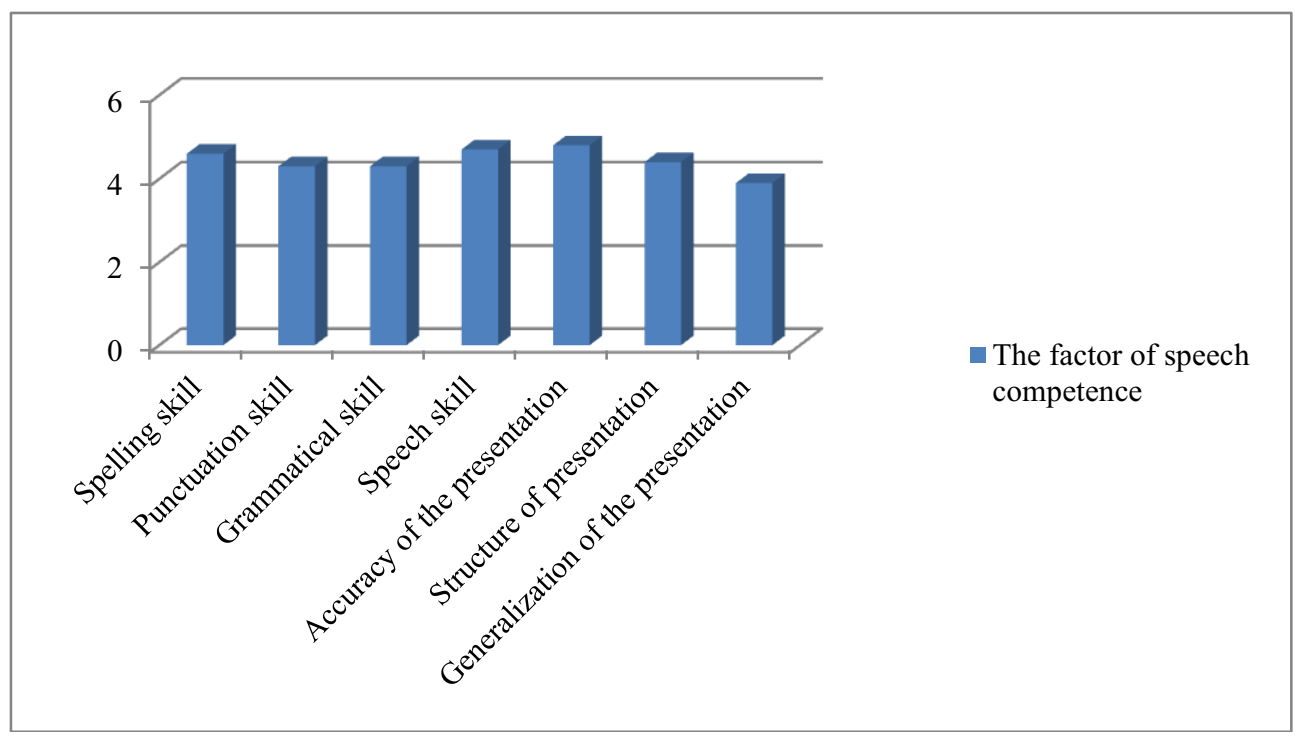

Fig. 2. The Average value of the factor of speech competence in students (forming experiment).

\section{Discussion}

In the course of the research, the concept of "speech competence" was introduced and given its author's definition. Speech competence is a psycholinguistic and professionalcommunicative readiness of the individual, reflecting the ability to carry out communicative and professional interaction, reflection and motivation of speech behavior, expressed in a certain level of knowledge of lexical, grammatical, phonetic laws of the language, the ability to construct statements and various types of texts, taking into account the specifics of professional activity [10].

In the course of the study, it was found that the criteria for speech competence are normality, communicative expediency, and professionalization of speech. Normirvannost (correctness of speech, orthology) takes into account the observance of language norms of word formation (norms for the formation of new words); orthoepic (or pronunciation norms); morphological; spelling; lexical; syntactic; punctuation; intonation. Communicative expediency implies clarity, accessibility, clarity, clarity, expressiveness, relevance, informative saturation, and imagery of speech [3].

Professionalization of speech as a criterion of speech competence of future specialists takes into account the rhetorical, pragmatic, orthological, stylistic aspects related to the knowledge of the features of professionally significant styles and genres necessary in working with official business documents and texts. 
As the main indicators of the formation of students ' speech competence, the following were identified:

a) have a developed oral and written speech;

b) ability to work with texts of various styles; with large amounts of information;

c) rhetorical and oratorical skills;

d) ability to observe the norms (orthoepic, lexical, word-forming, morphological, syntactic, spelling and punctuation).

The study found that there are factors that affect the formation of speech competencesubjective and objective, internal and external. Objective factors include the social environment; the conditions of professional and educational activities and its organization; the influence of the environment (the level of development of speech competence of the family environment, friends); information and communication environment; the level of socialization of the individual; the level of speech competence of University teachers. Subjective factors are the age of students; individual psychological characteristics of the person (temperament, emotional and volitional sphere of the person); motives and needs; level of development of verbal intelligence; attitude to the process of learning, selfdevelopment, self-improvement; vocabulary; skill of developing readers ' interests; barriers in communication (personal, social, communicative); skill of reflection of speech activity. External factors are the communicative environment in which the student lives and learns, the specifics of his activities, communication situations (communication situations can be divided into everyday, professional and educational). Internal factors are the level of education and upbringing of the individual; its psychological characteristics; motivation of the future specialist; the level of development of reflection of speech behavior.

The presented technology of development of speech competence of students is aimed at the formation of speech self-awareness of the future specialist; at the development of a value attitude to correct speech activity in professional discourse, creative activity, independence, motivation aimed at personal and professional growth. Conditions are created in the classroom so that the formation of a system of knowledge, skills and abilities is accompanied by the desire of students to independently replenish it, navigate in new information, as well as to form skills of self-observation and error correction. In this regard, the leading principle of managing the educational process at the University is the formation of motivational factors and reflection of students about the quality of their speech. This, without a doubt, contributes to the educational microenvironment of higher education institutions [11]

At the initial stage of training, methods of questioning, testing, and observation are used, which reveal the level of speech competence, motivation, psychological characteristics, and professional qualities of students. At the analytical stage, an "audience image" is created. At the organizational stage of the study, strategies of the educational process are selected (topics, thesaurus, methods of presenting material). The activity stage is a constructive interaction, creating problematic situations. At the diagnostic stage, the study of the level of formation of speech competence is carried out, such methods as questionnaires, testing, observation, analysis of analytical and reflexive activity of students are used. The reflexive stage includes assessment of the degree of solving the educational task, comparison of diagnostic results [2].

The process of implementing the technology of speech competence formation is based on a personal-oriented and practice-oriented methodological approaches, and therefore is associated with the need to split the training course into 2 parts: "Russian language and culture of speech" for students of the 1st year and "Fundamentals of speech competence of future specialists" for students of the last courses who have mastered specialized disciplines, immersed in the educational environment of the University. Thus, the names of speech disciplines take into account the degree of professionalization of students and, 
consequently, have the appropriate motivational potential for the formation of speech competence.

Given the prevalence of such psychology in the educational environment, we considered it effective to introduce a cross-cutting rating system in the educational process with the designation of the total amount of points by students, which allows them to get a successful result in the disciplines "Russian language and speech culture", "Fundamentals of speech competence of future specialists". This system allows students to constantly adjust their rating and receive appropriate points at any stage of educational activity when submitting mandatory educational products: tests, tests, public speaking, abstract, annotation, plan of oral public speech.

Pragmatic training is conducted during the entire period of work on a public speech and can have both oral and written forms. Depending on the level of training of the group, students are asked to perform tasks of a reproductive, productive or analytical-reflexive type. For example, when studying the module "Analytical text processing", only practical classes are provided. It is advisable to offer students different types of tasks. Tasks of the reproductive type involve familiarity with the theoretical material, which is located in the textbook. The exercises can be formulated as follows: write out all the terms related to this topic (keywords) from the scientific article, give them a concise definition; note the features of different types of texts: text-description, text-motivation, text-retrospection, evaluation text, contact text, determine the features of their similarities and differences; note the features of the typological structure of the text, the purpose of plans in educational and professional activities, types of plans; indicate the role of annotation in the development of analytical and synthetic abilities of the future specialist and the formation of skills of information work with the text, present the classification of annotations in the scientific literature, rules and techniques for creating annotations of different types. Outline the types of abstracts; the main requirements for the design of abstracts, features of the abstractreview. The task of reproductive type involves drawing up a plan for these scientific articles of the textbook, formulating questions on this topic.

Tasks of the productive type contain exercises for building skills. These include, for example, the following: edit the annotations suggested by the teacher, write down the text of the annotations in accordance with the spelling norm, edit the text of the annotation for an article on a professional topic selected by yourself, and make a plan for the article.

Analytical and reflexive tasks concern the assessment of their own level of development of knowledge, skills and abilities on this topic. For example, these tasks can be presented as a progress report.

In addition to training, the work on students ' pragmatic competence is based on the case-study method, aimed at analyzing real situations on the basis of which the group solves the problem taking into account the experience of others. The case method involves the use of a Bank of practical situations that represent clearly formed tasks (a package of practical situations). The case method can be implemented in the "module of etiquette situations in higher education", which consists of three blocks: 1) greeting formulas, saying goodbye to teachers; 2) speech behavior in the classroom; 3) communication in extracurricular time. The blocks contain speech situations that are "problematic" for students of the 1 st year in a new educational environment of the University. These include role-playing games that contribute to the development of speech competence of future specialists.

Thus, a set of methods for forming the foundations of speech competence of future specialists is aimed at productive educational activities and motivates students to speech activity as an element of the emerging professional image and characteristic of a creative personality. 
In the educational process of higher education institutions, forms and methods of active learning, electronic textbooks, group discussions, role-playing and business games, and other methods, forms and tools, computer and information technologies are not yet used enough to ensure the consolidation of a number of practical communication skills, to develop educational and cognitive activities of students [9].

\section{Conclusion}

Thus, the identified problems allow us to determine the main promising directions for the development of students ' speech competence. The established mechanisms should be implemented in the practice of teaching students, creating conditions for professionalization of speech activity. The study of this issue allows us to identify promising technologies for the formation of speech competence of specialists. The main promising directions of development of speech competence of students at the present stage is the formation of speech culture based on linguistic, cultural, situational, professional levels; taking into account the psychological characteristics of specialists, motivation factors and reflection of students on the quality of speech. The leading methods of speech training are teaching methods that correspond to a person-oriented technology, problem tasks (search-game, cognitive-search, role-playing games, discussions), language exercises, emotionalbehavioral tasks, and others). Training using these methods involves the formation of the ability to carry out speech activities that require a conceptual system (thesaurus) and understanding, a certain type of thinking that allows you to solve emerging problems and tasks in a specific professional environment.

\section{References}

1. O. Beletskaya, Questions of cultural studies 12, 69 (2018) http:// elibrary.ru "contents. asp? $\mathrm{id}=36452865$

2. S.V. Bobrova, M.A. Misharina, Technologies of development of intellect abilities of students in learning Russian language Basic tendencies of development of Russian and other Slavonic languages in the modern world: collection of scientific works on materials of the international scientific conference (Brno, 2014)

3. S.V. Bobrova, Bulletin of Moscow state University, series "Pedagogy" 4, 83 (2011) https://elibrary.ru/item.asp?id=18019011

4. O.B. Veremeichik, West. Minsk. state linguist. UN-TA. Series. 2, Pedagogy. Psychology. Methods of teaching foreign languages, http:// elibrary.ru" contents. asp? $\mathrm{id}=36452865$

5. T.V. Ivanchikova, Formation of speech competence of students of economic specialties of the University: situational approach: Diss ... doctor of pedagogical Sciences (M., Moscow. state regional UN-T, 2010) http:// search.rsl.ru" ru / record / 01004853914

6. V.Yu. Lipatova, Improving the text-forming activity of students in the study of rhetoric: dis. ... doctor of pedagogical Sciences (Moscow, Enlightenment, 2006) http: / / dissercat.com-Yes

7. V.V. Lozitsky, Development and system application of electronic educational and methodical complexes in social and humanitarian disciplines: problems and prospects (2013) http://cyberleninka.ru " article...by-distribution-socially

8. E. Lugovskaya, Actual issues of Philology, linguistics and journalism: materials of the scientific and practical conference of the faculty of Philology of PSU. T. G. Shevchenko on the results of scientific research in 2017 (Tiraspol, publishing house of Transnistria. 
UN-TA, 2018) http://litera.spsu.ru

9. O.A. Ovsyannikova, Optimization of the process of studying particles with computer support: dis. (Moscow, 2003)

10. O.A. Ovsyannikova, Law and education 11, 69 (2013) http://naukarus.com

11. O.A. Ovsyannikova, Formation of the "language personality" of specialists using the competence approach: monograph (Moscow, 2014)

12. Pedagogical encyclopedia (Moscow, Big Russian ENCYCLOPEDIA, 2012) http://gigabaza. ru

13. Dictionary of practical psychologist (Minsk, Urozhd, 1998) http://PsychoAnalitik.by

14. L.N. Sobchik, Standardized multi-factor method of personality research Methods Minnesota multidimensional personality inventory, http://www.rg.ru/2012/05/09/nauka-dok.html

15. I. Shifron-Boreyko, Russian as a foreign language and diagnostics of speech development: XIX international scientific conference. Technologies of teaching Russian as a foreign language and diagnostics of speech development (Minsk, 2017) http:// elibrary.ru " contents. asp? id=36452865

16. C. Herron, S.P. Cole, C. Corrie, S. Dubreil, Journal Of Modern Language 84(4) 518

17. J. Mull, Research in the journal of SelfAccess Learning Journal 4(1), 43 (2013) 